\title{
FIELD IDENTIFICATION OF MYOTIS YUMANENSIS AND MYOTIS LUCIFUGUS: A MORPHOLOGICAL EVALUATION
}

\author{
Thomas J. Rodhouse ${ }^{1}$, Shonene A. Scott ${ }^{2,4}$, Patricia C. Ormsbee ${ }^{3}$, and Jan M. Zinck ${ }^{2}$
}

\begin{abstract}
Myotis lucifigus and Myotis yumanensis are 2 species of bats subject to potentially high rates of misidentification because they are often difficult to differentiate in the hand under field conditions. We tested the utility of a suite of external morphological characteristics frequently cited in regional keys to differentiate the 2 species in the field. Forearm length, dorsal pelage sheen, ear color, and forehead slope were examined from 101 bats captured in central Oregon during 2002-2003. Post hoc genetic analysis was performed on tissue samples collected from the 101 bats to confirm identification. Forearm lengths overlapped considerably between species. Only $18 \%$ of M. yumanensis and $17 \%$ of $M$. lucifugus were correctly identified with probability $\geq 95 \%$ using forearm length alone. Pelage sheen, ear color, and forehead slope successfully identified $96 \%, 82 \%$, and $77 \%$ of individual bats, respectively. When forearm length was considered together with other traits, identification rates ranged from $92 \%$ to $20 \%$. Ability to correctly identify $M$. yumanensis was 2-6 times greater than for M. lucifugus. Pelage sheen was useful in our study; however, using this character required a subjective decision from the observer, and the result often contradicted other characters for species identification stated in regional keys. For these reasons, we recommend that morphological features be used judiciously and only as supportive criteria for field identification in combination with voucher echolocation calls and genetic confirmation.
\end{abstract}

Key words: Myotis yumanensis, Myotis lucifugus, Chiroptera, bats, Oregon, identification.

Myotis lucifugus (little brown myotis) and Myotis yumanensis (Yuma myotis) are 2 morphologically similar species of bats common to western North America that can be difficult to distinguish in the field (Barbour and Davis 1969, Fenton and Barclay 1980, Nagorsen and Brigham 1993, Verts and Carraway 1998). Species accounts and dichotomous keys frequently suggest that forearm length and qualitative diagnostic morphological characteristics, including pelage sheen, ear color, and forehead slope, can be useful in distinguishing the 2 species in the field (Barbour and Davis 1969, Nagorsen and Brigham 1993, Verts and Carraway 1998). Myotis lucifugus is reported to typically exhibit longer forearms than $M$. yumanensis, glossy dorsal pelage, ears darker than dorsal pelage, and a gradually sloping forehead. Myotis yumanensis is considered to have shorter forearms, short and dull dorsal pelage, light ears matching the dorsum, and a steep sloping forehead. However, many individuals of these 2 species exhibit intermediate morphological characteristics and can be hard to identify in areas of sympatry (Barbour and
Davis 1969, Harris 1974, Parkinson 1979, Herd and Fenton 1983, Verts and Carraway 1998). Characteristics such as dorsal pelage sheen and ear color can be difficult to determine at night or in poor lighting typical of conditions in the field and are open to subjective judgment. Forehead slope, typically evaluated from prepared museum specimens, has been suggested as a potentially useful field diagnostic, but this character can be difficult to discern in live specimens (Nagorsen and Brigham 1993, Verts and Carraway 1998).

Recording echolocation calls is widely recognized as an important diagnostic tool for identification of bats, and along with new genetic techniques, these methods have greatly improved our ability to identify M. lucifugus and M. yumanensis species without sacrificing individuals for museum specimens (Gannon et al. 2003, Szewczak 2004, Zinck et al. 2004, Weller et al. 2007). However, successful identification remains problematic for field studies in which genetic and acoustic tools are unavailable. Further difficulties arise because many observers who are required to identify bats in

\footnotetext{
${ }^{1}$ National Park Service Upper Columbia Basin Network, Central Oregon Community College, 2600 NW College Way, Bend, OR 97701. E-mail: tom_rodhouse@nps.gov

${ }^{2}$ Portland State University, Department of Biology, Box 751, Portland, OR 97201.

${ }^{3}$ Willamette National Forest, USDA Forest Service, 211 E 7th Avenue, Eugene, OR 97401

${ }^{4}$ Present address: University of Maine, 5755 Nutting Hall, Room 210, Orono, ME 04469.
} 
the western United States have limited field experience and are permitted to focus only a small part of their professional responsibilities on chiropteran studies (Weller and Zielinski 2006). Persistence of forearm length and subjectively measured qualitative characteristics in published keys used to distinguish these 2 species underscores the need for additional evaluations across the range of sympatry.

During 2002-2003, while contributing to a vertebrate inventory of the John Day Fossil Beds National Monument and several larger projects (e.g., Weller et al. 2007), we conducted an investigation on a subset of bats captured in order to evaluate the diagnostic utility of dorsal pelage sheen, ear color, forehead slope, and forearm length. For this examination, we genetically confirmed identification of $M$. lucifugus and M. yumanensis after field identifications were recorded from bats captured along the John Day River and several tributaries in Wheeler and Grant counties, Oregon.

\section{Methods}

We captured bats and collected samples from Myotis at 11 locations along a 161-km stretch of the John Day River and 3 major tributaries in August-September 2002 and in June-August 2003. Bats were captured with mist nets (Avinet, Inc., Dryden, NY), which were placed over water and in flyways. All bats were handled following the animal care and use guidelines of the American Society of Mammalogists (Gannon et al. 2007), and procedures were approved by the University of Idaho Institutional Animal Care and Use Committee.

Bats belonging to the 2 target species were differentiated from other bats with reliable key characteristics (e.g., Nagorsen and Brigham 1993, Verts and Carraway 1998). For these 2 species, tentative field identification was made after morphological characteristics had been evaluated. We differentiated juvenile from adult bats by noting the presence of unfused epiphyses (Anthony 1988).

Forearm length was measured using dial calipers accurate to within $0.1 \mathrm{~mm}$. Logistical constraints precluded us from adequately designing a study that would have supported evaluation of differences between observers. Therefore, the qualitative morphological characteristics of pelage sheen, ear color, and fore- head slope were evaluated by a single observer (TJR) to eliminate interobserver bias. At night, bats were evaluated in the hand using a headlamp for illumination. Each characteristic was described dichotomously, and bats possessing intermediate or difficult-to-distinguish features were forced into 1 of 2 main categories. Pelage sheen was described as either dull or glossy. Dull bats typically exhibited shorter, finer fur with a dull sheen. Glossy bats exhibited a "bronzy" sheen, with qualitatively longer and coarser guard hairs. Ear color was described as either light and matching the dorsal pelage or dark and not matching the dorsal pelage (i.e., darker than the dorsal pelage). Forehead slope was described as either steep or gradual, and this characteristic was evaluated by gently pressing the soft pad of the index finger into the forehead of the bat and noting whether a distinctive step between rostrum and frontal bones was present. This particular measure was intended to provide a field approximation for evaluations of forehead slope commonly made in museums with prepared specimens of Myotis (Parkinson 1979, van Zyll de Jong 1985, Verts and Carraway 1998). Based on published keys (e.g., Verts and Carraway 1998), we expected M. yumanensis to have forearms <35 $\mathrm{mm}$ long, dull pelage, light brown ears that matched the dorsal pelage color, and steep foreheads. Conversely, we expected M. lucifugus to have forearms $\geq 35 \mathrm{~mm}$ long, glossy pelage, dark ears, and shallow foreheads.

We used biopsy punches $(3 \mathrm{~mm})$ to collect wing tissues for genetic identification (Wilmer and Barratt 1996). Genetic identification of all samples was accomplished through amplification of the Myspl/Mysp2 190-base-pair fragment of the 16S ribosomal subunit gene, followed by restriction fragment length polymorphism (RFLP) analysis as described by Zinck et al. (2004). For all samples identified as M. lucifugus, we determined the subspecies by sequencing the Mysp1/Mysp2 and Mysp3/ Mysp4 fragments outlined by Zinck et al. (2004).

We compared the resulting proportions of assignments to species and morphological categories with $2 \times 2$ contingency tables. We used the log-likelihood $G$ test for independence with the Williams' correction, as described by Sokal and Rohlf (1981), to determine the probability of obtaining the observed or more extreme table results under the null hypothesis of independence between identity of species based on 
TABle 1. Percentage (and probability, $\pi$ ) of individuals correctly identified by species, and proportion of bats assigned to each morphological category. Individuals correctly identified were those Myotis yumanensis with forearm lengths $<35 \mathrm{~mm}$, dull pelage, light ears, and steep foreheads and Myotis lucifugus with forearm lengths $\geq 35$ $\mathrm{mm}$, glossy pelage, dark ears, and shallow foreheads. Probabilities $(\pi)$ should be interpreted as the probability that a bat exhibiting a particular morphological characteristic was properly classified with respect to its genetic determination. For example, a bat with dull pelage had a 98\% chance of being M. yumanensis, whereas a bat with glossy pelage had a $91 \%$ chance of being M. lucifugus.

\begin{tabular}{ccc}
\hline & M. yumanensis & M. lucifugus \\
\hline Forearm length \% $(\pi)$ & $90(0.77)$ & $48(0.75)$ \\
$<35 \mathrm{~mm}(n=77)$ & 60 & 17 \\
$\geq 35 \mathrm{~mm}(n=24)$ & 6 & 18 \\
Pelage sheen \% $(\pi)$ & $95(0.98)$ & $97(0.91)$ \\
Dull $(n=63)$ & 62 & 1 \\
Glossy $(n=37)$ & 3 & 34 \\
Ear color \% $(\pi)$ & $78(0.94)$ & $91(0.68)$ \\
Light $(n=54)$ & 51 & 3 \\
Dark $(n=44)$ & 14 & 30 \\
Forehead slope \% $(\pi)$ & $88(0.79)$ & $57(0.71)$ \\
Steep $(n=73)$ & 58 & 15 \\
Gradual $(n=28)$ & 8 & 20 \\
Combined characters $\%$ & 67 & 24 \\
"Correct" $(n=51)$ & 43 & 8 \\
"Incorrect" $(n=46)$ & 21 & 25 \\
\hline
\end{tabular}

morphological characteristics and genetic data. We computed species identity probabilities for individual bats exhibiting particular combinations of forearm length and categorical morphological characteristics using logistic regression ( $\mathrm{R}$ version 2.4.1, 2006, the $\mathrm{R}$ Foundation for Statistical Computing). Four models were constructed that reflected our primary interest in the performance of individual qualitative morphological characteristics after accounting for forearm length. We tallied, by species, the number of individual bats correctly identified with probability $\geq 95 \%$ from fitted values for each model. We tested for an effect of species membership on the odds of correct assignment by computing odds ratios. Correctly assigned bats were those that presented expected morphological characteristics given their genetic identity. We did not test for an effect of $M$. lucifugus subspecies identification on correct assignment, because of the small numbers of 2 of the 3 subspecies in the study.

\section{RESULTS}

We collected tissue samples and evaluated morphological characteristics from 101 bats that were either M. lucifugus or M. yumanensis. We captured 8 bats exiting from day roosts in a building and under a bridge, and we captured the remaining 95 bats with mist nets over water. Based on post hoc genetic analysis, 66 individuals were $M$. yumanensis, representing $65 \%$ of bats in the study, and 35 individuals were M. lucifugus, representing $35 \%$ of bats in this study. Morphological observations were missing from 4 bats, which resulted in sample sizes of 97 to 101 for analyses of single and combined morphological characteristics. Composition of age and sex for the sample included 78 adults and 23 juveniles, and 58 males and 43 females. We documented 3 subspecies of $M$. lucifugus in our study, and of 30 sequenced samples, 21 were M. l. lucifugus, 5 were M. $l$. carissima, and 4 were M. l. alascensis. We captured all 3 subspecies at the same location in a single night on several occasions.

Overall, identification of species based on the 4 morphological characteristics was highly variable. Percentage and probability of individuals correctly assigned to species and proportions of each species assigned to each morphological category are reported in Table 1 . Of 101 bats, 98 (97\%) were correctly identified with at least 1 morphological characteristic. We found pelage sheen most successful at predicting species, with $96 \%$ success. Success with ear color was $82 \%$, and both forearm length and forehead slope were used to correctly identify $77 \%$ of bats. When all 4 characteristics were used in combination, only $52 \%$ of bats exhibited all 4 characteristics associated with their species consistently. Observed proportions of individuals correctly identified to species based on a single morphological characteristic were greater than expected under the null hypothesis of independence $(P<0.01, G$ test for independence). We did not detect evidence of an effect by age $(P=0.32)$ or sex $(P=0.85)$ on correct assignment for variables. For example, not a single young bat was misclassified by pelage sheen. Figure 1 illustrates the range and degree of overlap in forearm lengths between species. Six M. yumanensis had forearm lengths $\geq 35 \mathrm{~mm}$, although none exceeded 35.3 $\mathrm{mm}$. Seventeen M. lucifugus had forearms $<35$ $\mathrm{mm}$ long, including 1 adult female whose forearm measured $32.9 \mathrm{~mm}$. We did not detect any relationship between age and forearm length for either species $(P>0.5$, Student's $t$ test). 


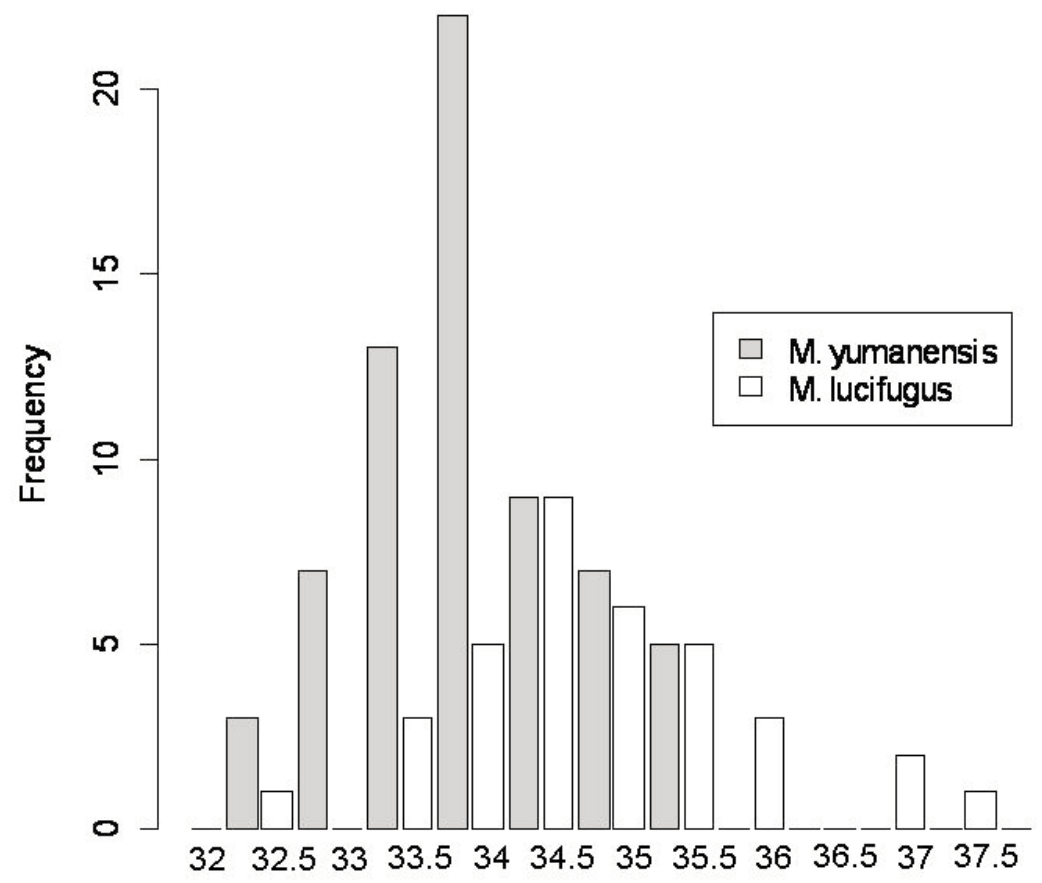

\section{Forearm Length (mm)}

Fig. 1. Frequencies of forearm length for Myotis yumanensis $(n=66)$ and Myotis lucifugus $(n=35)$ measured in the John Day Basin, Oregon, 2002-2003.

TABLE 2. Model results for each combination of forearm length (Arm) with pelage sheen (Pelage), ear color (Ear), and forehead slope (Head). $\triangle \mathrm{AIC}$ is the difference in AIC values between the model with the most support given the observed data and all subsequently supported models. Model coeffcients ( $\beta$ values) were used to compute fitted probabilities of species membership for observed values of morphological characters. The last 2 table columns present the proportion of individuals correctly assigned to species with probability $\geq 95 \%$ for Myotis yumanensis (MYYU) and Myotis lucifugus (MYLU).

\begin{tabular}{lrcccccccc}
\hline Model & \multicolumn{1}{c}{$\Delta$ AIC } & $\beta_{0}$ & $s_{\bar{x}}\left(\beta_{0}\right)$ & $\beta_{1}$ & $s_{\bar{x}}\left(\beta_{1}\right)$ & $\beta_{2}$ & $s_{\bar{x}}\left(\beta_{2}\right)$ & MYYU & MYLU \\
\hline Arm + Pelage & 0.00 & 54.22 & 24.19 & -1.65 & 0.71 & 6.25 & 1.31 & 0.92 & 0.66 \\
Arm + Ear & 25.49 & 75.24 & 19.90 & -2.21 & 0.58 & 3.90 & 0.90 & 0.63 & 0.36 \\
Arm + Head & 25.49 & 65.37 & 14.76 & -1.92 & 0.43 & 2.04 & 0.67 & 0.33 & 0.20 \\
Arm & 87.14 & 69.90 & 14.30 & -2.01 & 0.41 & - & - & 0.18 & 0.17 \\
\hline
\end{tabular}

Logistic regression models evaluating the influence of forearm length (arm), pelage sheen (pelage), ear color (ear), and forehead slope (head) on the odds of an individual bat belonging to either species are presented in Table 2 . Using Akaike's information criterion (AIC), the model with forearm length and pelage sheen had the most support and predictive utility. This model contained over $99 \%$ of the AIC weight and was almost 10 times as likely to be the best model than the 2nd-ranked model, which included forearm length and ear color. The top model correctly assigned $92 \%$ of $M$. yumanensis and $66 \%$ of $M$. lucifugus, with fitted probability values $\geq 95 \%$. Predictive success declined considerably in each additional model (Table 2).

Based on morphological characteristics, $M$. yumanensis was more often correctly assigned to species than M. lucifugus was. The odds of correctly identifying $M$. yumanensis were 6.3 , 2.9 , and 2 times greater than the odds for correctly identifying $M$. lucifugus on the basis of 
pelage sheen, ear color, and forehead slope, respectively $(P<0.01,2$-sided test for equality of population odds). The proportions of correct assignment for each M. lucifugus for which post hoc genetic sequencing provided subspecies identification were 0.25 for $M$. $l$. alascensis $(n=4), 0.55$ for M. l. lucifugus $(n=$ $21)$, and 0.6 for M. l. carissima $(n=5)$.

\section{DisCussion}

The morphological characteristics of forearm length, pelage sheen, ear color, and forehead slope appear to have some value, at least in our study area, as aids in field identification of M. lucifugus and M. yumanensis. Pelage sheen was successful when considered by itself, and it significantly improved modeled probabilities when added to forearm length. In our study, almost all individuals were successfully identified by at least 1 characteristic. Juveniles also were as identifiable as adults with these characteristics, although we suspected that forearm length and pelage sheen might differ in young bats. We saw no obvious effect of subspecific status for M. lucifugus on identification success rate, although the numbers of M. l. alascensis and M. l. carissima in the sample were too few to rigorously test this. The relatively moderate proportions of correct assignment suggest a lack of strong effect, although we suspect that the presence of 3 subspecies in our sample accounts for some variability leading to problems of identification using morphological characteristics for $M$. lucifugus.

Overall, however, our results indicate that these morphological characteristics are highly variable and inconsistent in their combination within individual bats, particularly for $M$. lucifugus. Considerable random variation in the expression of these characteristics seems to exist within individuals. For example, a bat exhibiting a "correct" or expected forehead slope, given its genetic identity, can not necessarily be expected to exhibit the other associated characteristics consistently. This has considerable implications for field observers, because a bat of unknown identity is likely to exhibit contradictory evidence of its true identity, based on these characteristics.

Although our results demonstrate some potential predictive utility of pelage sheen, and to a lesser extent ear color and forehead slope, we remain concerned that the opportu- nity for misidentification remains high when these characteristics are used in concert in the field. The required decisions are subjective, difficult to reproduce among observers, and are subject to poor lighting and observer fatigue. Two earlier studies that addressed the use of these characteristics (Harris 1974, Parkinson 1979) both dismissed the utility of pelage sheen, although given the absence of definitive confirmation of species identification in their studies, the possibility of "contamination" by misidentified species is possible. Requirement for subjective decision making and the observed variability in the combination of diagnostic characteristics within individuals suggest that use of these characteristics is problematic.

Pelage sheen was a particularly successful diagnostic characteristic in our study, and is consistently recommended in regional keys (Nagorsen and Brigham 1993, Verts and Carraway 1998). It is likely that with practice and access to genetic post hoc confirmation, individual observers can cultivate an ability to reliably discern dull and glossy bats within a geographic area, as was done in our study. However, the geographic variation in morphology that has been reported for these species is substantial and use of these characters across large areas should be made with caution (Harris and Findley 1962, Barbour and Davis 1969, Harris 1974). This scenario of needing to develop a high level of expertise is reminiscent of the debate surrounding qualitative evaluation of bat call sequences (Barclay 1999, O’Farrell et al. 1999). As a general strategy, however, reliance on acquired expertise is clearly unsatisfactory given the range of experience represented among field technicians. In a survey across the United States and Canada, Weller and Zielinski (2006) found that a majority of bat biologists possessed $<5$ years of experience and spent $<20 \%$ of their professional duties working with bats. Those data underscore the need for readily learned and repeatable methods for identification of bats, such as when acoustic recording equipment is available. Weller et al. (2007) observed that the characteristic frequency of echolocation calls and forearm length for these 2 species overlapped considerably, but these characteristics were effective when combined into a model-based identification tool. Nonetheless, acoustic tools are not always available, and field observers 
must be informed of the risks inherent with any protocol used to identify species.

Future studies like ours would benefit by involving multiple observers in order to address interobserver bias. We were unable to examine this adequately in our study, and it is not possible to discern to what degree our diagnostic success using pelage sheen was driven by a particularly astute observer. It is also possible that bats captured in our area are unusually homogenous in their expression of pelage sheen. Collection of voucher specimens for museum preservation also would be of value, although given the longevity of bats and their uncertain conservation status, we strongly caution against this becoming a widespread practice. We also suspect that adequate numbers of museum specimens are already available to support a broader investigation. Of course, inspection of live bats in a field setting presents its own unique challenges and was the primary objective for our study.

Conceptually, we consider our evaluation to be a quality-control strategy in which precision, bias, and reproducibility of instruments and measures are considered integral to the reporting of results. Without these kinds of information, the participating scientific community at large is unable to adequately evaluate and interpret the significance of research findings. Published articles involving species that are difficult to differentiate and subject to misidentification often do not report details on how field diagnosis was obtained, leaving readers with no alternative but to trust the skill and experience of the observers involved. Recent advances in analytical approaches relying on presence-absence data, such as occupancy modeling (Mackenzie et al. 2006), are inherently appealing to investigators working with bats but make strict assumptions about correct identification (i.e., no false positives) that may be underappreciated by less-experienced biologists. We suggest that approaches similar to ours be conducted by other investigators whenever possible, as a type of quality assurance. Collection of tissue from bats for genetic studies has become increasingly routine, and when applied to a small subset of captured animals for quality control, it requires setting aside only a small proportion of a research budget.

In the specific case of $M$. lucifugus and $M$. yumanensis, we encourage other researchers working in areas of sympatry to conduct and report evaluations of field diagnostics alongside core projects. Our results clearly indicate that it would be premature to completely dismiss these qualitative characteristics in the absence of additional studies from other areas. In addition, important ancillary information on the taxonomy and distribution of these 2 species and their subspecies also may be discovered through these types of efforts. For example, we were surprised to discover 3 subspecies of M. lucifugus in our study area, which contradicted past reports (Dalquest 1947, Parkinson 1979, Hall 1981, Verts and Carraway 1998).

In conclusion, we recommend judicious use of these characters to differentiate M. lucifugus and $M$. yumanensis in conjunction with voucher echolocation calls whenever possible. Weightof-evidence generated from multiple diagnostic sources should be considered instead of reliance on any particular favored characteristic. The inherent risks of misidentification and the likelihood of seeing contradictory evidence in other key characteristics must be appreciated, and we encourage greater transparency in the reporting of field identification protocols. Genetic testing or other confirmatory tools should be routinely used on a subset of study individuals in order to estimate identification error.

\section{ACKNOWLEDGMENTS}

This project was conducted as part of several larger projects that were supported by the National Park Service Upper Columbia Basin Network Inventory and Monitoring Program, the Great Basin Cooperative Ecosystem Studies Unit, and the USDA Forest Service. K. Hyde of the John Day Fossil Beds National Monument provided additional support and funding. We are grateful for the substantial field support provided by M. McCaffrey and M. Smith and for laboratory support provided by D. Duffield, R. Hull, and L. Patrick. We thank the associate editor, 2 anonymous reviewers, and $\mathrm{T}$. Weller for their many helpful comments during the preparation of this manuscript.

\section{Literature Cited}

Anthony, E.L.P. 1988. Age determination in bats. Pages 47-58 in T.H. Kunz, editor, Ecological and behavioral methods for the study of bats. Smithsonian Institution, Washington, DC.

Barbour, R.W., and W.H. Davis. 1969. Bats of America. University Press of Kentucky, Lexington. 
BARCLAY, R.M.R. 1999. Bats are not birds-a cautionary note on using echolocation calls to identify bats: a comment. Journal of Mammalogy 80:290-296.

DALQuest, W.W. 1947. Notes on the natural history of the bat, Myotis yumanensis, in California, with a description of a new race. American Midland Naturalist 38: 224-247.

FEnton, M.B., AND R.M.R. BARClay. 1980. Myotis lucifugus. Mammalian Species 142:1-8.

Gannon, W.L., M.J. O'Farrell, C. Corben, and E.J. BEDRICK. 2003. Call character lexicon and analysis of field recorded bat echolocation calls. Pages 478484 in J.A. Thomas, C.F. Moss, and M. Vater, editors, Echolocation in bats and dolphins. University of Chicago Press, Chicago, IL.

Gannon, W.L., R.S. Sikes, and Animal Care and Use Committee of the American Society of MamMALOGISTS. 2007. Guidelines of the American Society of Mammalogists for the use of wild mammals in research. Journal of Mammalogy 88:809-823.

HaLl, E.R. 1981. The mammals of North America. 2nd edition. John Wiley \& Sons, Inc., New York.

HaRRIs, A.H. 1974. Myotis yumanensis in interior southwestern North America, with comments on Myotis lucifugus. Journal of Mammalogy 55:589-607.

Harris, A.H., AND J.S. Findley. 1962. Status of Myotis lucifugus phasma and comments on variation in Myotis yumanensis. Journal of Mammalogy 43:192199.

Herd, R.M., And M.B. Fenton. 1983. An electrophoretic, morphological, and ecological investigation of a putative hybrid zone between Myotis lucifugus and Myotis yumanensis (Chiroptera: Vespertilionidae). Canadian Journal of Zoology 61:2029-2050.

MacKenzie, D.I., J.D. Nichols, J.A. Royle, K.H. PolLOCK, L.L. BAILEY, AND J.E. Hines. 2006. Occupancy estimation and modeling: inferring patterns and dynamics of species occurrence. Elsevier, London.

Nagorsen, D.W., and R.M. Brigham. 1993. The bats of British Columbia. UBC Press, Vancouver, British Columbia, Canada.
O'Farrell, M.J., C. Corben, W.L. Gannon, and B.W. MiLler. 1999. Confronting the dogma: a reply. Journal of Mammalogy 80:297-302.

PARKInson, A. 1979. Morphological variation and hybridization in Myotis yumanensis sociablis and Myotis lucifugus carissima. Journal of Mammalogy 60:489504.

SOKAL, R.K., AND FJ. RoHLF. 1981. Biometry: the principle and practice of statistics in biological research. W.H. Freeman, San Francisco, CA.

SZEWCZAK, J.M. 2004. Advanced analysis techniques for identifying bat species. Pages 121-127 in R.M. Brigham, E.K.V. Kalko, G. Jones, S. Parsons, and H.J.G.A. Limpens, editors, Bat echolocation research: tools, techniques, and analysis. Bat Conservation International, Austin, TX.

VAN ZyLL DE Jong, C.G. 1985. Handbook of Canadian mammals. 2. Bats. National Museums of Canada, Ottawa, Ontario.

Verts, B.J., AND L.N. Carraway. 1998. Land mammals of Oregon. University of California Press, Berkeley.

Weller, T.J., S.A. Scott, T.J. Rodhouse, P.C. Ormsbee, AND J.M. ZINCK. 2007. Field identification of the cryptic vespertilionid bats Myotis lucifugus and Myotis yumanensis in the Pacific Northwest. Acta Chiropterologica 9:133-147.

WELLER, T.J., AND W.J. Zielinski. 2006. Using an internet questionnaire to characterize bat survey efforts in the United States and Canada. Wildlife Society Bulletin 34:1000-1008.

Wilmer, J.W., and E. Barratt. 1996. A non-lethal method of tissue sampling for genetic studies of chiropterans. Bat Research News 37:1-3.

Zinck, J.M., D.A. Duffield, And P.C. Ormsbee. 2004. Primers for identification and polymorphism assessment of vespertilionid bats in the Pacific Northwest. Molecular Ecology Notes 4:239-242.

Received 6 March 2008 Accepted 24 April 2008 